\title{
Solvent extraction and characterization of neutral lipids in Oocystis sp.
}

\author{
Renil Anthony ${ }^{1}$ and Ben Stuart ${ }^{2 *}$ \\ ${ }^{1}$ Department of Mechanical Engineering, Ohio University, Athens, OH, USA \\ ${ }^{2}$ Department of Civil Engineering, Ohio University, Athens, OH, USA
}

\section{Edited by:}

Umakanta Jena, Desert Research Institute, USA

Reviewed by:

Anoop Singh, Ministry of Science and Technology, India

István Barabás, Technical University of Cluj-Napoca, Romania

Daniel Geller, University of Georgia, USA

\section{*Correspondence:}

Ben Stuart, 122 Stocker Center,

Athens, $\mathrm{OH}, 45701$, USA

e-mail: stuart@ohio.edu
Microalgae are a favorable feedstock for bioproducts and biofuels due to their high oil content, fast growth rates, and low resource demands. Solvent lipid extraction efficiency from microalgae is dependent on algal strain and the extraction solvent. Four non-polar extraction solvents were evaluated for the recovery of neutral cellular lipids from microalgae Oocystis sp. (University of Texas at Austin LB2396). Methylene chloride, hexane, diethyl ether, and cyclohexane were selected as the extraction solvents. The lipid extracts were derivatized and analyzed using gas chromatography-mass spectroscopy. All solvent extracts contained hexadecanoic acid, linoleic acid, and linolenic acid; accounting for $70 \%$ of total lipid content with a proportional wt $\%$ composition of the three fatty acids, except for the hexane extracts that showed only hexadecanoic acid and linoleic acid. While not statistically differentiated, methylene chloride proved to be the most effective solvent for Oocystis sp. among the four solvents tested with a total average neutral lipid recovery of $0.25 \%$ of dry weight followed by diethyl ether $(0.18 \%)$, cyclohexane $(0.14 \%)$, and hexane $(0.11 \%)$. This research presents a simple methodology to optimize the selection of lipid specific extraction solvents for the microalgal strain selected.

Keywords: microalgae, bioproducts and biofuels, solvent extraction, Oocystis, lipids

\section{INTRODUCTION}

Microalgae have demonstrated great potential as a feedstock for bioproducts and biofuels. Microalgae have extremely high growth rates with biomass doubling times as short as $3.5 \mathrm{~h}$ (Chisti, 2007). Microalgae can be grown in wastewater or brackish water thereby, offsetting the requirement for fresh water. In addition to high growth rates, the lipid content of some microalgae strains has been reported as high as $80 \mathrm{wt} \%$ of dry biomass when subjected to stressful growth conditions that maximize lipid content (Chisti, 2007).

Microalgae can be fractionated into its major biochemical compounds, namely lipids, carbohydrates, and proteins. These biochemical compounds can then be converted into high value or commodity products such as nutraceuticals/pharmaceuticals, biodiesel from lipids, biosolvents, biogas from carbohydrates, aquaculture or animal feed from proteins, and other bioproducts such as pigments (phycocyanin), antioxidants (biliverdin), or antibacterials (Anthony et al., 2013). Operating on a multiproduct platform will be helpful in minimizing the risks of market fluctuations. Hence, while developing extraction methods or processes, care should be taken to avoid damaging any valuable biochemical compounds. Utilizing such a biorefinery approach to produce several products from microalgae has the potential to greatly improve the economic viability and promote industrial scale production and processing of microalgae.

Biodiesel, an alternative diesel fuel, is made from renewable biological sources such as vegetable oils and animal fats (Ma and Hanna, 1999). A variety of feedstock can be used to produce biodiesel such as virgin vegetable oil, waste vegetable oil, animal fats, and non-edible oils such as Jatropha oil, neem oil, castor oil, and others. The choice of feedstock for biodiesel is contingent upon the natural resources of the particular region where biodiesel production is desired (Demirbas, 2007). Although promising, techno-economic assessments for conventional biodiesel production using crop plants have proved them to be unsustainable due their low photosynthetic efficiency, huge fresh water requirement to reach maturity, and slow growth rates (Li et al., 2008). Moreover, the use of edible oils for biodiesel is controversial in that it may result in an imbalance in the food supply chain.

Conventional methods of oil extraction such as mechanical pressing, supercritical fluid extraction, enzymatic extraction, hydrothermal liquefaction, ultrasonic assisted extraction, and osmotic shock possess certain technological limitations and/or are economically unsuitable for large-scale microalgal lipid extraction (Herrero et al., 2005). Solvent extraction, on the other hand is a relatively easier method that has been widely used for lipid extraction from microalgae and considered economical for commercial scale systems (Mercer and Armenta, 2011).

Solvent extraction of algal lipids is carried out by organic solvents such as benzene, hexane, acetone, chloroform (Mercer and Armenta, 2011), methylene chloride (Chen et al., 1981), ethanol, isopropanol (Smedes, 1999), or a combination of organic solvents depending on the products desired. Non-polar solvents such as hexane, cyclohexane, and methylene chloride show higher recovery of cellular non-polar or neutral lipids as compared to polar solvents such as methanol and ethanol, which have higher recovery of membrane associated polar lipids (Sakthivel et al., 2011). Furthermore, specific algal strains significantly influence 
solvent selection for lipid extraction. Shen et al. (2009) performed lipid extractions on microalgae Scenedesmus dimorphus and Chlorella protothecoides using hexane and hexane/ethanol solvent systems and found higher lipid recovery with hexane. Fajardo et al. (2007) reported higher lipid recovery with Phaeodactylum tricornutum using hexane/ethanol solvent system. In a similar study, methylene chloride recovered the most neutral lipids from Chlorella sp. when compared to hexane and chloroform (Guckert et al., 1988). These findings suggest that in addition to the solvent type, the efficiency of lipid recovery is also algal strain dependent.

In this study, four non-polar solvents were chosen as the extraction media to recover neutral lipids from microalgae Oocystis sp. using the Soxhlet method. Oocystis sp. was chosen due to the potential for lipid production as evaluated under the Aquatic Species Program (ASP). It was desired to determine if the fatty acid profile and quantities from Oocystis sp. would be suitable for use as a bioproduct and biofuel feedstock. The four solvents selected were methylene chloride, hexane, diethyl ether, and cyclohexane. These particular solvents were selected based on previous lipid extraction studies on microalgae (Guckert et al., 1988; Shen et al., 2009) and marine samples (Smedes, 1999). The lipid extracts from each solvent were derivatized and analyzed on combined gas chromatography-mass spectroscopy (GC-MS). For this study, no attempt was made to maximize the lipid content of Oocystis sp. by nutrient stressing or manipulating other growth conditions. The objectives of this research were; (1) to identify the most efficient solvent among the four in terms of non-polar lipids extracted, and (2) to quantify and characterize the cellular fatty acid profile of Oocystis sp.

\section{MATERIALS AND METHODS}

The algal strain Oocystis sp. was obtained from the University of Texas at Austin (UTEX) culture collection (UTEX \# LB2396). Nile Red (9-diethylamino-5H-benzo[a]phenoxazine-5one), Fatty Acid Methyl Esters (FAMEs) mix (C8-C24) and internal standard methyl myristate $(\mathrm{C} 15 \mathrm{H} 30 \mathrm{O} 2)$ were obtained from Sigma Aldrich (St. Louis, MO, USA) and used as received. HPLC grade n-hexane, methanol, cyclohexane, diethyl ether, and methylene chloride were obtained from Fisher Scientific (Pittsburg, PA, USA). Oocystis sp. was grown in closed photobioreactors in artificial sea water media $(\mathrm{pH}=7)($ McLachan, 1964) as prescribed by Csavina (2008) at an average temperature of $25^{\circ} \mathrm{C}$ and $0.1 \mathrm{mmol} / \mathrm{s} / \mathrm{m}^{2}$ light intensity with a 16:08 light/dark cycle. Aeration was provided to facilitate mixing.

Prior to lipid extraction, Nile Red staining was used to detect the non-polar lipid content of Oocystis sp. Nile Red is lipid specific and only stains the non-polar lipids within the cell. The fluorescence of the non-polar lipids after being stained with Nile Red can be measured easily on a spectrophotometer $(520 \mathrm{~nm}$ ) (Roessler et al., 1998). According to the lipid optimization studies performed by Csavina et al. (2011), a Nile Red reading of 2000 Fluorescent Standard Units (FSU) suggested a high amount of neutral lipids in the cells. The Nile Red staining procedure followed by Csavina (2008) was adopted to determine time of harvesting. Oocystis sp. was harvested by coagulation with a pre-determined dosage of aluminum sulfate. The cells were collected by gravity settling and washed several times with $1.0 \mathrm{M} \mathrm{NaOH}$ to remove the associated aluminum hydroxide prior to oil extraction.

To a sample size of $10 \mathrm{~g}$ dry algae, methanol was added while grinding using mortar and pestle to lyse the cells (Guckert et al., 1988). The lysed cells were dried and placed in a cellulose extraction thimble (Whatman no. 2810-338) in the Soxhlet apparatus and the solvents refluxed for $8 \mathrm{~h}$. Extractions were performed in triplicate for each of the four solvents. The derivatization procedure comprised of adding $1 \mathrm{~mL}$ of toluene to the reaction test tube containing the extracts followed by $2 \mathrm{~mL}$ of $1 \%$ sulfuric acid in methanol. The test tube was sealed and heated to $50^{\circ} \mathrm{C}$ for $8 \mathrm{~h}$. After cooling, $5 \mathrm{~mL}$ of $5 \%$ sodium chloride in water was added and shaken to dissolve the water soluble elements and encourage phase separation. One milliliter of the top organic phase was transferred to a GC vial for analysis.

The compounds in the lipids extracts were analyzed using a combination of gas chromatography (GC-HP6890) and mass spectrometry (MS-5973) using the parameters provided in Table 1. External standard comprising of FAME mix (C8-C24) was used to determine the response factors of the compounds relative to the internal standard, methyl myristate. The response factors were calculated by Eq. 1 as:

$$
F=\frac{W_{\text {int }} \times A_{i}}{A_{\text {int }} \times W_{i}}
$$

where $i=1,2,3, \ldots, n$ (where $n$ is defined as the $n$th FAME), $W_{\text {int }}$ and $W_{i}$ are the weights of the internal standard and the compound peak in consideration, respectively, $A_{\text {int }}$ and $A_{i}$ are the areas of internal standard and the peak in consideration, respectively, and $F$ is the response factor (Grob and Barry, 2004).

For a specific response factor $F$, the weight of the unknown can be calculated by Eq. 2 (Grob and Barry, 2004) as:

$$
W_{c}=\frac{A_{c}}{A_{\mathrm{int}}} \times F_{c} \times W_{\mathrm{int}}
$$

where, $W_{\text {int }}$ and $W_{c}$ are the weights of internal standard and unknown (C), respectively, $A_{\text {int }}$ and $A_{c}$ are the areas of internal standard and unknown, respectively, and $F_{c}$ is the response factor for the compound of interest.

\section{RESULTS AND DISCUSSION GRAVIMETRIC AND NILE RED ANALYSIS}

Nile Red values measured by Csavina (2008) for Oocystis sp. on the 7 th day of growth was $2000 \mathrm{FSU}$, which amounted to a $615 \%$

Table 1 | Gas chromatography parameters for the analysis of FAMEs.

\begin{tabular}{ll}
\hline Parameters & Values \\
\hline Inlet temperature & $260^{\circ} \mathrm{C}$ \\
Injection volume & $1 \mu \mathrm{L}$ \\
Initial temperature & $60^{\circ} \mathrm{C}$ \\
Ramp & $15^{\circ} \mathrm{C} / \mathrm{min}$ \\
Final temperature & $270^{\circ} \mathrm{C}$ \\
Carrier gas & Helium
\end{tabular}


increase in fluorescence suggesting a relatively high neutral lipid content in the cells. For the current research, the average Nile Red fluorescence obtained in the exponential growth phase was 2459 FSU, which represented approximately a 750\% increase in fluorescence. Oocystis sp. was harvested at this stage by aluminum sulfate and washed prior to oil extraction. Gravimetric analysis revealed a methylene chloride extract weight of $0.54 \mathrm{~g}$ followed by hexane, diethyl ether, and cyclohexane with $0.23,0.20$, and $0.20 \mathrm{~g}$, respectively. One of the possible reasons for higher weight of methylene chloride extracts could be due to the higher polarity index of methylene chloride (3.1) when compared to other solvents, which could have better dissolved the polar components of the biomass such as residual media salts or membrane lipids. The gravimetric analysis measured the total extractable material from Oocystis sp., which could include cellular lipids, chlorophyll, proteins, membrane lipids, and residual media salts and the coagulant aluminum hydroxide.

\section{RESPONSE FACTOR}

The FAME mix (C8-C24) (external standard) was spiked with methyl myristate (internal standard) and was run to obtain the response factors for the relevant compounds (Figure 1). The relevant compounds in the unknown samples were determined as hexadecanoic acid methyl ester (C16:0), linoleic acid methyl ester (18:2), and linolenic acid methyl ester (18:3) eluting at 13.08, 14.07, and $14.17 \mathrm{~min}$, respectively. The response factors for hexadecanoic
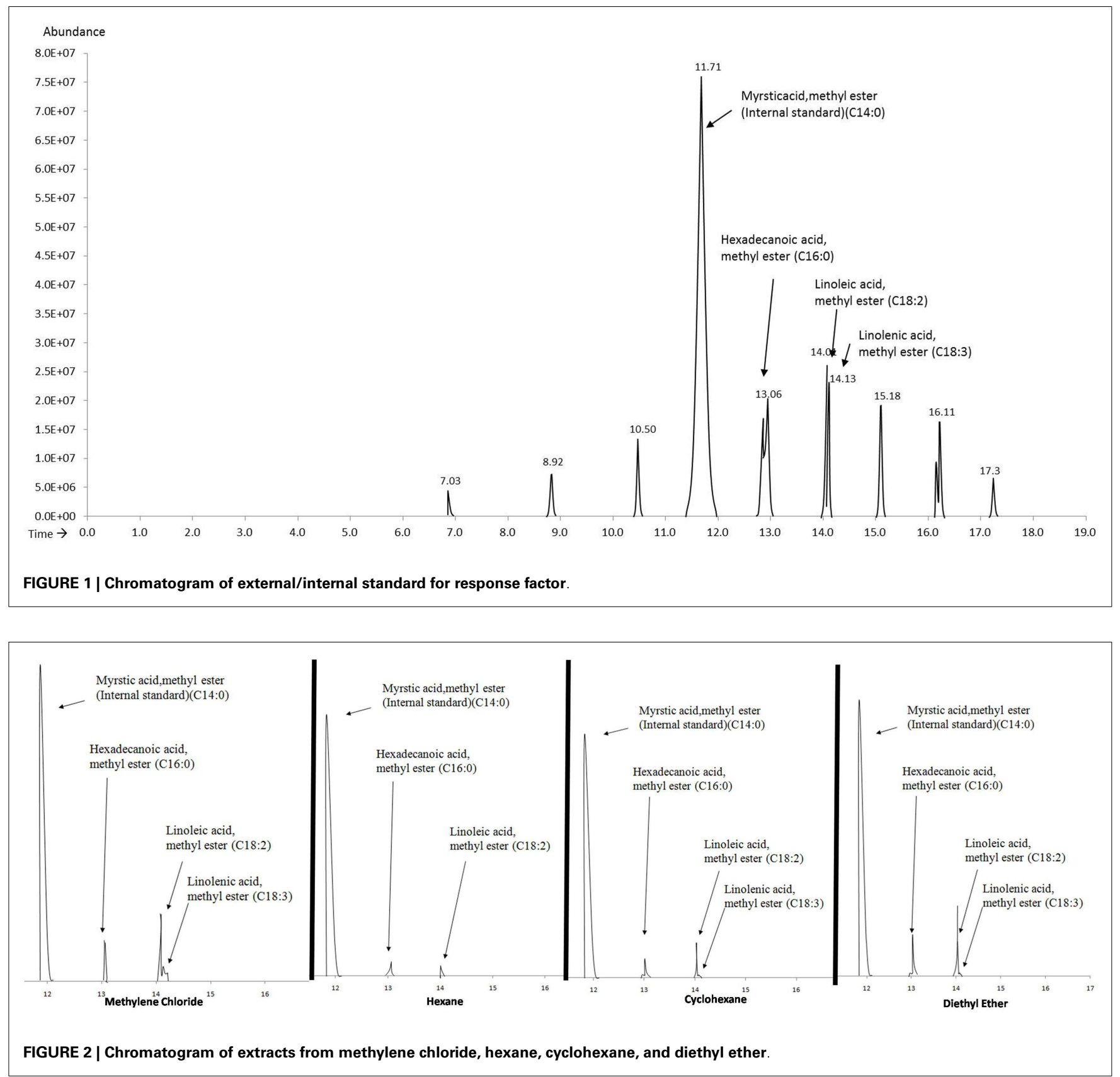
Table 2 | Summary of FAMEs from Oocystis sp. extracted with the four solvents.

\begin{tabular}{lcccccc}
\hline & $\begin{array}{l}\text { Total FAMEs } \\
\text { (mg/g dry wt) }\end{array}$ & $\begin{array}{l}\text { Coefficient of } \\
\text { variation (\%) }\end{array}$ & Dry wt (\%) & $\begin{array}{l}\text { Hexadecanoic acid methyl } \\
\text { ester (C16:0) \% (w/w) }\end{array}$ & $\begin{array}{l}\text { Linoleic acid methyl } \\
\text { ester (C18:2) \% (w/w) }\end{array}$ & $\begin{array}{l}\text { Linolenic acid methyl } \\
\text { ester (C18:3) \% (w/w) }\end{array}$ \\
\hline Methylene chloride & $2.5 \pm 0.1$ & 8.3 & 0.25 & 42.7 & 54.6 & 54.8 \\
Diethyl ether & $1.8 \pm 0.2$ & 38.1 & 0.18 & 42.5 & 55.6 & 3.6 \\
Cyclohexane & $1.4 \pm 0.2$ & 18.7 & 0.14 & 40.9 & 52.9 \\
Hexane & $1.1 \pm 0.1$ & 14.2 & 0.11 & 47.0 & ND \\
\hline
\end{tabular}

$N D$, non-detectable.

Sums may not equal $100 \%$ due to rounding error.

Table 3 | Ryan-Einot-Gabriel-Welsch post hoc comparison of lipid yields from extraction solvents.

\begin{tabular}{|c|c|c|c|}
\hline REGWO grouping & Mean & $N$ & Solvent \\
\hline$A$ & 24.8 & 3 & Methylene chloride \\
\hline$A$ & 17.6 & 3 & Diethyl ether \\
\hline B & 14.4 & 2 & Cyclohexane \\
\hline B & 10.7 & 3 & Hexane \\
\hline
\end{tabular}

Means with the same letter are not significantly different.

acid methyl ester, linoleic acid methyl ester, and linolenic acid methyl ester as calculated using Eq. 1 were $0.57,0.45$, and 0.30, respectively.

\section{QUANTITATIVE ANALYSIS OF FATTY ACID METHYL ESTERS}

Methyl myristate was used as the internal standard for quantifying the FAMEs in the derivatized extracts. A known volume of methyl myristate was added to the GC vial prior to analysis and the compounds were quantified using Eq. 2. The four extracts consistently showed three peaks eluting between 13 and $15 \mathrm{~min}$, which through mass spectroscopy were identified as hexadecanoic acid methyl ester, linoleic acid methyl ester, and linolenic acid methyl ester except the hexane extracts for which linolenic acid was non-detectable. Figure 2 shows the chromatograms of the extracts of the four solvents indicating the internal standard and the compounds in the sample.

Table 2 presents the percent composition of the total FAMEs extracted. One-way analysis of variance (ANOVA) was performed on the mean values of total neutral lipids for the four solvents with a 95\% confidence level with the Ryan-Einot-Gabriel-Welsch (REGWQ) test procedure employed for post hoc comparison using Statistical Analysis Software (SAS 9.3). As shown in the REGWQ grouping in Table 3, there was a significant difference between the weights of the FAMEs extracted by methylene chloride as compared to cyclohexane and hexane, however, there was no significant difference between methylene chloride and diethyl ether. Comparing the average weights of FAMEs extracted, methylene chloride was the highest followed by diethyl ether, cyclohexane, and hexane. The extracts from the four solvents showed nearly proportional percent composition of hexadecanoic acid methyl ester, linoleic acid methyl ester, and linolenic acid methyl ester as shown in Table 2. Although there are other fatty acids in Oocystis sp. in much lower concentrations, these three fatty acids represent about $70 \%$ of the fatty acid profile (Patil et al., 2007) and were the only ones to have been sufficiently produced to be detected as per our growth, extraction, and analytical conditions.

Based on the evaluations conducted under the ASP, Oocystis sp. was selected as a candidate for potential bioproduct and biofuel production. Four non-polar solvents were evaluated for their extractability of neutral lipids from Oocystis sp. Of the four solvents, methylene chloride (on average) extracted the highest amount of neutral lipids followed by diethyl ether, cyclohexane, and hexane. The success of any bioproduct/biofuel program relies on identifying high lipid producing algal strains and the respective optimum extraction conditions. The economics of bioproduct/biofuel production can further be improved by employing a biorefinery platform to fractionate the biomass thereby, allocating the economic and environmental burdens to all the bioproducts generated, accordingly.

\section{ACKNOWLEDGMENTS}

This work was funded in part by a grant from the US Department of Energy (award number DE-FG36-08GO88083).

\section{REFERENCES}

Anthony, R. J., Ellis, J. T., Sathish, A., Rahman, A., Miller, C. D., and Sims, R. C. (2013). Effect of coagulant/flocculants on bioproducts from microalgae. Bioresour. Technol. 149, 65-70. doi:10.1016/j.biortech.2013.09.028

Chen, I., Shen, C., and Sheppard, A. (1981). Comparison of methylene chloride and chloroform for the extraction of fats from food products. J. Am. Oil Chem. Soc. 58, 599-601. doi:10.1007/BF02672373

Chisti, Y. (2007). Biodiesel from microalgae. Biotechnol. Adv. 25, 294-306. doi:10. 1016/j.biotechadv.2007.02.001

Csavina, J. L. (2008). The Optimization of Growth Rate and Lipid Content from Select Algae Strains. thesis. Available at: http://etd.ohiolink.edu/view.cgi?acc_ num $=$ ohiou 1215529734

Csavina, J. L., Stuart, B. J., Guy Riefler, R., and Vis, M. L. (2011). Growth optimization of algae for biodiesel production. J. Appl. Microbiol. 111, 312-318. doi:10.1111/j.1365-2672.2011.05064.x

Demirbas, A. (2007). Importance of biodiesel as transportation fuel. Energy Policy 35, 4661-4670. doi:10.1016/j.enpol.2007.04.003

Fajardo, A. R., Cerdán, L. E., Medina, A. R., Fernández, F. G. A., Moreno, P. A. G., and Grima, E. M. (2007). Lipid extraction from the microalga Phaeodactylum tricornutum. Eur. J. Lipid Sci. Technol. 109, 120-126. doi:10.1002/ejlt.200600216

Grob, R. L., and Barry, E. F. (2004). Modern Practice of Gas Chromatography, 4th Edn. Hoboken, NJ: Wiley-Interscience.

Guckert, J. B., Cooksey, K. E., and Jackson, L. L. (1988). Lipid solvent systems are not equivalent for analysis of lipid classes in the microeukaryotic green alga, Chlorella. J. Microbiol. Methods 8, 139-149. doi:10.1016/0167-7012(88)90015-2

Herrero, M., Martín-Álvarez, P. J., Javier Señoráns, F., Cifuentes, A., and Ibáñez, E. (2005). Optimization of accelerated solvent extraction of antioxidants from Spirulina platensis microalga. Food Chem. 93, 417-423. doi:10.1016/j.foodchem. 2004.09.037 
Li, Y., Horsman, M., Wu, N., Lan, C. Q., and Dubois-Calero, N. (2008). Biofuels from Microalgae. Biotechnol. Prog. 24, 815-820. doi:10.1021/bp070371k

Ma, F., and Hanna, M. A. (1999). Biodiesel production: a review. Bioresour. Technol. 70, 1-15. doi:10.1016/S0960-8524(99)00025-5

McLachan, J. (1964). Some considerations of the growth of marine algae in artificial media. Can. J. Microbiol. 10, 769-782. doi:10.1139/m64-098

Mercer, P., and Armenta, R. E. (2011). Developments in oil extraction from microalgae. Eur. J. Lipid Sci. Technol. 113, 539-547. doi:10.1002/ejlt.201000455

Patil, V., Torsten, K., Elisabeth, O., Gjermund, V., and Gislerød, H. R. (2007). Fatty acid composition of 12 microalgae for possible use in aquaculture feed. Aquacult. Int. 15, 1-9. doi:10.1007/s10499-006-9060-3

Roessler, P., Sheehan, J., Dunahay, T., Benemann, J. (1998). A Look Back at the U.S. Department of Energy's Aquatic Species Program: Biodiesel from Algae. Books LLC. Reference Series.

Sakthivel, R., Elumalai, S., and Mohommad Arif, M. (2011). Microalgae lipid research, past, present: a critical review for biodiesel production, in the future. $J$. Exp. Sci. 2, 29-49. Available at: http://jexpsciences.com/index.php/jexp/article/ view/9559

Shen, Y., Zhijian, P., Wenqiao, Y., and Enrong, M. (2009). Effect of nitrogen and extraction method on algae lipid yield. Int. J. Agricult. Biol. Eng. 2, 51-57. doi:10.3965/ijabe.v2i1.86
Smedes, F. (1999). Determination of total lipid using non-chlorinated solvents. Analyst 124, 1711-1718. doi:10.1039/A905904K

Conflict of Interest Statement: The authors declare that the research was conducted in the absence of any commercial or financial relationships that could be construed as a potential conflict of interest.

Received: 18 September 2014; accepted: 19 December 2014; published online: 20 January 2015.

Citation: Anthony R and Stuart B (2015) Solvent extraction and characterization of neutral lipids in Oocystis sp. Front. Energy Res. 2:64. doi: 10.3389/fenrg.2014.00064

This article was submitted to Bioenergy and Biofuels, a section of the journal Frontiers in Energy Research.

Copyright (C) 2015 Anthony and Stuart. This is an open-access article distributed under the terms of the Creative Commons Attribution License (CC BY). The use, distribution or reproduction in other forums is permitted, provided the original author(s) or licensor are credited and that the original publication in this journal is cited, in accordance with accepted academic practice. No use, distribution or reproduction is permitted which does not comply with these terms. 